\title{
PLaser annealing of silicon surface defects for photovoltaic applications
}

\author{
Zeming Sun and Mool C. Gupta \\ Charles L. Brown Department of Electrical and Computer Engineering, University of Virginia, \\ Charlottesville, VA, 22903
}

\begin{abstract}
High power lasers are increasingly used for low cost fabrication of solar cell devices. High power laser processes generate crystal defects, which lower the cell efficiency. This study examines the effect of low power laser annealing for the removal of high power laser induced surface defects. The laser annealing behavior is demonstrated by the significant decrease of photoluminescence generated from dislocation-induced defects and the increase of band-to-band emission. This annealing effect is further confirmed by the X-ray diffraction peak reversal. The dislocation density is quantified by observing etch pits under the scanning electron microscope (SEM). For as-melted samples, the dislocation density is decreased to as low as $1.01 \times 10^{6} \mathrm{~cm}^{-2}$ after laser annealing, resulting in an excellent surface carrier lifetime of $920 \mu \mathrm{s}$ that is comparable to the value of $1240 \mu$ s for the silicon starting wafer. For severely defective samples, the dislocation density is decreased by 4 times and the surface carrier lifetime is increased by 5 times after laser annealing.

keywords: Laser annealing; Defects; Silicon; Photovoltaics; Photoluminescence
\end{abstract}

\section{Introduction}

Currently, silicon based solar cells continue to play an important role in the photovoltaic market, accounting for over $90 \%$ of global annual production [1]. The high power laser-based processes are widely being investigated for photovoltaic applications, in order to simplify the fabrication processes, to avoid high temperature processes, and to achieve lower manufacturing cost [2-7]. High power lasers can achieve a noncontact processing at localized positions and large area through scanning. These advantages have enabled applications of laser for direct writing [2], microtexturing [3], doping [4], ablation [5], cutting [6], edge isolation [7], and laserfired contacts [2].

However, the high power laser processes can induce crystallographic defects [8] and could generate the amorphous phase [9] in the surface regions where laser energy is absorbed. The laser induced defects and amorphous phases can dramatically decrease the photovoltaic device efficiency due to the deterioration of electrical properties and particularly the higher charge carrier recombination rate [8]. Thus, it is necessary to minimize or eliminate these laser-induced defects and obtain crystalline phase through a post annealing process.

Previous research over the last decades has well studied the use of conventional furnace and rapid thermal annealing (RTA) for making high efficiency solar cells [10,11]. Recently, laser annealing has attracted considerable attention due to its selective, localized, and potentially costeffective traits. Researchers have explored laser annealing of ion implanted silicon [12,13]. Unfortunately, the laser annealing of defects in silicon after the high power laser processes is not well understood and requires further investigations. Therefore, it is essential to explore the laser annealing for a wider acceptance of the laser-based photovoltaic technology.

In this work, we demonstrate the laser annealing behavior to minimize surface defects and especially dislocations in monocrystalline silicon after high power laser processes. Also, we present the results on the crystallization of laser induced amorphous phases. Moreover, we 
quantify the dislocation density and evaluate the surface carrier lifetime after laser annealing.

\section{2, Experimental}

All the investigated samples were polished p-type boron-doped monocrystalline silicon wafers (FZ), with a crystalline orientation of $<100>$, a thickness of $300 \mu \mathrm{m}$, and a resistivity of approximately $1 \Omega-\mathrm{cm}$. The wafer surface was first cleaned by a standard procedure: $\mathrm{HCl}$ and diluted $\mathrm{HF}$ to react with any ionic contaminants, high concentration $\mathrm{HNO}_{3}$ to remove any organic contaminants, and diluted HF to dissolve away the surface oxide.

A pulsed fiber laser with a wavelength of $1064 \mathrm{~nm}$ and a pulse duration of $50 \mathrm{~ns}$ was used to process the wafers. The full laser power was $30 \mathrm{~W}$ at $100 \%$ set point and the repetition rate in this work was $30 \mathrm{kHz}$. The schematic of laser experiment setup is shown in Fig. 1. A laser beam with a Gaussian profile first entered mirror galvanometer that controlled the laser scanning direction and speed. The sample position was adjusted to the laser focal plane through the vertical movement of working stage. A raster scanning with multiple loops was performed to achieve the large-area laser processing. In order to guarantee overlapping of laser treated regions, the spacing of parallel lines was chosen as $20 \mu \mathrm{m}$ and the scanning speed was $50 \mathrm{~mm} / \mathrm{s}$. As shown in Fig. 2(a), the diameter of laser spot was $63 \mu \mathrm{m}$ and $68 \%$ overlapping was achieved between laser lines.

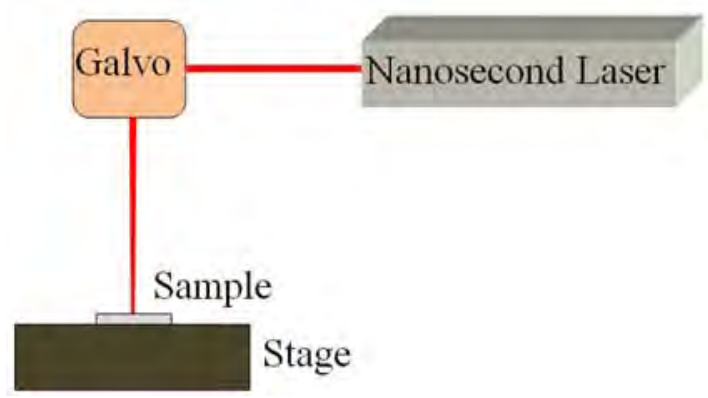

Fig. 1 Schematic of laser experiment setup.

The laser experiments were divided into two stages: laser processing under high fluences and post laser annealing under low fluences. The reason to choose high laser fluences for the initial processing was that most laser-based silicon solar cell processing requires the silicon melting. Based on preliminary experiments, two high laser fluences were selected to create two different defect characteristics: $1.28 \mathrm{~J} / \mathrm{cm}^{2}$-fluence (as-melted) and $1.60 \mathrm{~J} / \mathrm{cm}^{2}$-fluence (severely defective). The melting of silicon started under $1.28 \mathrm{~J} / \mathrm{cm}^{2}$ laser fluence and the surface roughness begun to be significant after $1.6 \mathrm{~J} / \mathrm{cm}^{2}$.

Afterwards, the processed samples were annealed under various low laser fluences. To understand the influences of laser parameters on the annealing behavior, we studied four different low laser fluences: $0.19 \mathrm{~J} / \mathrm{cm}^{2}, 0.38 \mathrm{~J} / \mathrm{cm}^{2}, 0.57 \mathrm{~J} / \mathrm{cm}^{2}$, and $0.76 \mathrm{~J} / \mathrm{cm}^{2}$.

In Fig. 2(b), the SEM cross-section of a single laser scan shows a melt depth of around $8 \mu \mathrm{m}$. The melted region in an imperfect Gaussian shape is mainly due to the off-normal angle of incident laser beam to the sample surface. The roughness generated during sample cutting can still be observed in the unmelted region. Despite the absorption depth of about $100 \mu \mathrm{m}$ in silicon under $1064 \mathrm{~nm}$ laser irradiation [14], the melting threshold combined with absorption depth led to near surface melting. Thus, we characterized the surface defects using $532 \mathrm{~nm}$ and $660 \mathrm{~nm}$ lasers with a small penetration depth of $1 \mu \mathrm{m}$ in silicon[14]. 

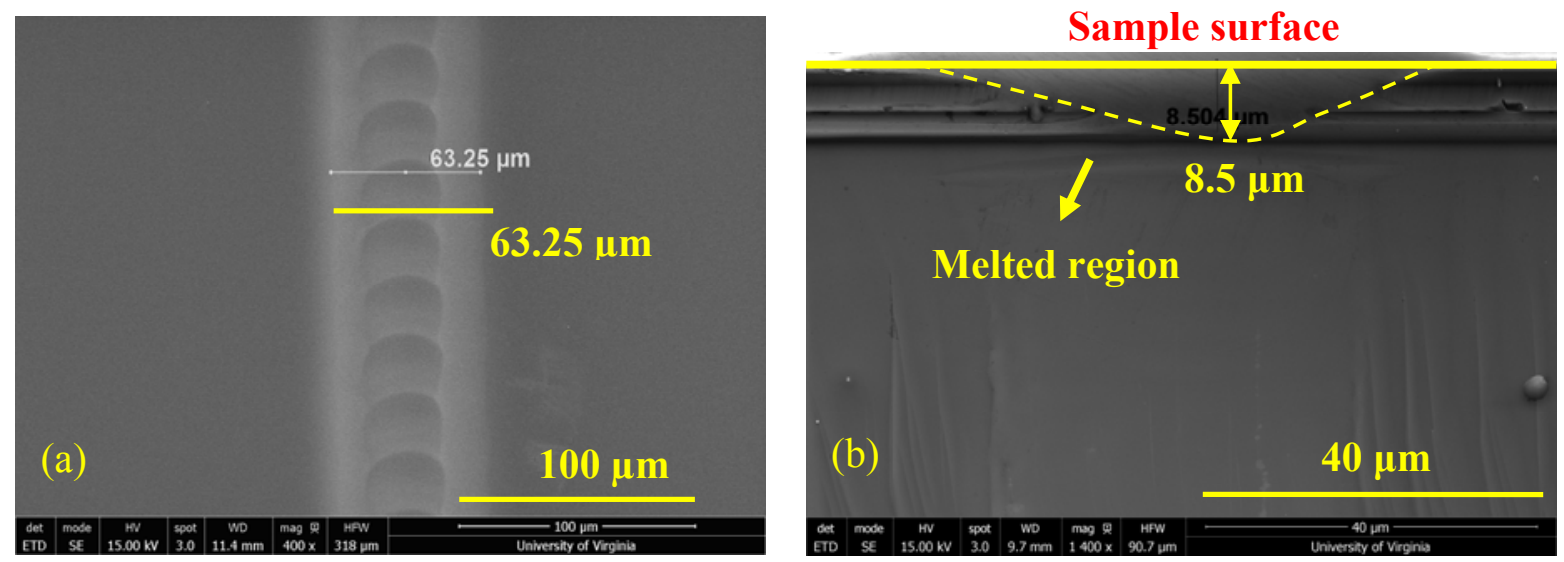

Fig. 2 SEM images of a single laser scan under $1.60 \mathrm{~J} / \mathrm{cm}^{2}$ showing the laser spot size and melt depth: (a) Top view, (b) Cross-section view. The dashed line shows the edge of the melted region.

Photoluminescence (PL) measurements were performed to understand the band-to-band and dislocation-induced emission. In the PL setup, a continuous wave (CW) laser with a wavelength of $532 \mathrm{~nm}$ (DPSS, Melles Griot) was used as the excitation source. The laser power (maximum power: $2.5 \mathrm{~W}$ ) was chosen as $1.7 \mathrm{~W}$ for a strong carrier excitation in the silicon samples. An optical chopper (SR540) was used to change the CW laser into pulses with a frequency of 100 Hz. A lock-in amplifier (SR 830 DSP) together with the chopper was used to amplify the excited PL signal. After the PL light signal passed through the long-pass band and green-light filters, it was directed into the spectrometer (iHR 320) and collected by an InGaAs photoreceiver at $-40^{\circ} \mathrm{C}$.

To further study the internal stress, an X-ray diffractometer (XRD, PANalytical X'Pert PRO MRD) was used. The angular step size was set as $0.002^{\circ}$ for achieving a high resolution.

Moreover, the dislocation etch was carried out by placing the samples in a mixed solution of $\mathrm{HNO}_{3}, \mathrm{HF}$, and HAc for 6 hours [15]. The preferential etching occurred at the dislocation sites due to the intensive strain field around the dislocations. These etch pits were observed using scanning electron microscope (SEM). To calculate the dislocation density, we randomly chose three areas on the sample under SEM and counted the number of etch pits within each area, thus the dislocation density was determined by Dislocation Density $=\frac{\text { Number of etch pits }}{\text { Area }}$. An area of $42 \mu \mathrm{m} \times 63 \mu \mathrm{m}$ (Magnification: 2000×) under SEM was chosen in order to clearly distinguish the etch pits while ensuring a large statistical-sample size.

Finally, the photoconductive decay (PCD) [16] method was used to evaluate the charge carrier lifetime after laser annealing. A CW laser (CUBE 660-60C) with a wavelength of $660 \mathrm{~nm}$ was used to induce excess carriers in silicon samples, and this light source was controlled by a function generator (3314A) to produce a square waveform with a frequency of $30 \mathrm{~Hz}$. The photogenerated current was collected using two metal probes and the current was displayed on an oscilloscope. Thus, the charge carrier lifetime was measured by the light-induced conductance change.

\section{3, Results and discussion}

The morphology studied using SEM for different laser processed samples is shown in Fig. 3. In Fig. 3(a), it is observed that the laser scanned lines begin to appear under $1.28 \mathrm{~J} / \mathrm{cm}^{2}$ fluence showing the start of silicon melting. After the laser fluence increases to $1.60 \mathrm{~J} / \mathrm{cm}^{2}$, the scanned lines with a width of $27 \mu \mathrm{m}$ can be clearly observed in Fig. 3(b), and the surface roughness 
becomes more severe, indicating a more significant melting and vaporization. The melting and resolidification occur at high heating and cooling rates under $1.60 \mathrm{~J} / \mathrm{cm}^{2}$ fluence, thus they led to the generation of micro cracks, internal stress, and crystallographic defects such as dislocations.
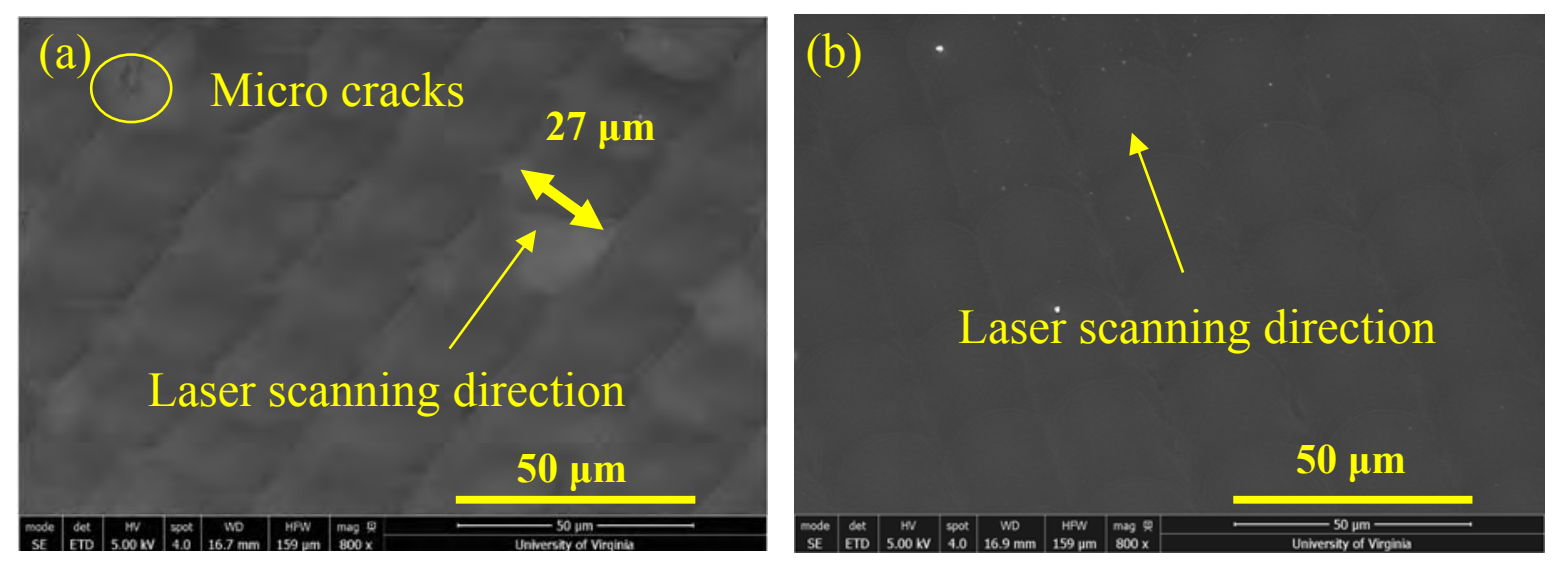

Fig. 3 SEM images after laser processing under different fluences: (a) $1.60 \mathrm{~J} / \mathrm{cm}^{2}$, (b) $1.28 \mathrm{~J} / \mathrm{cm}^{2}$.

The PL emission peak at $1340 \mathrm{~nm}$ wavelength arises due to the presence of dislocations [17] and emission at $1160 \mathrm{~nm}$ wavelength is from band-to-band transition. The PL spectra due to dislocation-induced emission and band-to-band emission after laser annealing at different fluences are shown in Fig. 4 and Fig. 5, respectively. The dislocation energy state is located between the valence band and conduction band, thus less defects (dislocations) after annealing lead to more band-to-band carrier recombination and PL emission, attributing to a higher PL intensity in Fig. 5 and in contrast a lower PL intensity in Fig. 4.

As shown in Fig. 4, the initial peak intensity for $1.60 \mathrm{~J} / \mathrm{cm}^{2}$-fluence processed samples is 3 times higher than $1.28 \mathrm{~J} / \mathrm{cm}^{2}$-fluence processed samples, indicating a much higher dislocation density induced by the significant melting. Fig. 4(a) shows that the initial peak intensity of 60 (arbitrary units) decreases to a value of 15 after laser annealing at $0.38 \mathrm{~J} / \mathrm{cm}^{2}$. This significant drop of dislocation-related peak indicates the decrease of dislocation density and demonstrates the laser annealing behavior for defect minimization.

By comparing the results under different laser annealing fluences, we find that a low fluence of $0.19 \mathrm{~J} / \mathrm{cm}^{2}$ is not sufficient to remove dislocations. If the fluence is increased as high as 0.57 $\mathrm{J} / \mathrm{cm}^{2}$, the dislocation peak starts to rebound, indicating the laser energy is high enough to induce defects. Thus, annealing at $0.38 \mathrm{~J} / \mathrm{cm}^{2}$ fluence shows the best results for removing dislocations.

As shown in Fig. 4(b), the $1.28 \mathrm{~J} / \mathrm{cm}^{2}$-fluence processed sample also shows a drop of dislocation peak after laser annealing, but the decrease of peak intensity is limited due to the small amount of dislocations in the initial sample.

As shown in Fig. 5(b), the PL due to band-to-band emission increases by a factor of 2 after the laser annealing at $0.38 \mathrm{~J} / \mathrm{cm}^{2}$ fluence for $1.28 \mathrm{~J} / \mathrm{cm}^{2}$-fluence processed samples. Since the band-to-band peak can reflect the overall information of defects, this peak increase again demonstrates the annealing behavior at $0.38 \mathrm{~J} / \mathrm{cm}^{2}$ laser fluence. However, the peak increase is only observed in $1.28 \mathrm{~J} / \mathrm{cm}^{2}$-fluence processed samples which should have a much larger amount of amorphous phase than $1.60 \mathrm{~J} / \mathrm{cm}^{2}$-fluence processed samples. Thus, the reason for this peak increase is mainly contributed by the crystallization of amorphous phase. 

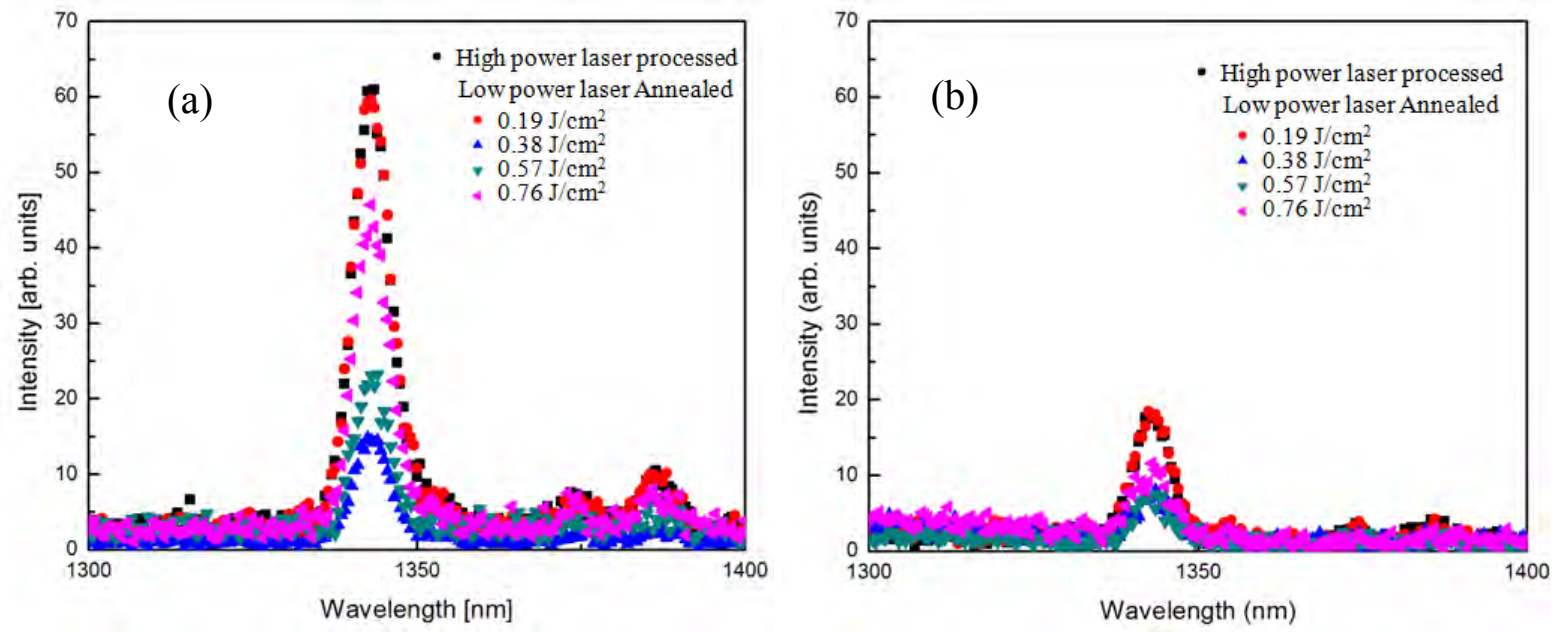

Fig. 4 PL due to dislocation-induced emission after laser annealing at different fluences: (a) $1.60 \mathrm{~J} / \mathrm{cm}^{2}$ - fluence processed samples, (b) $1.28 \mathrm{~J} / \mathrm{cm}^{2}$ - fluence processed samples.
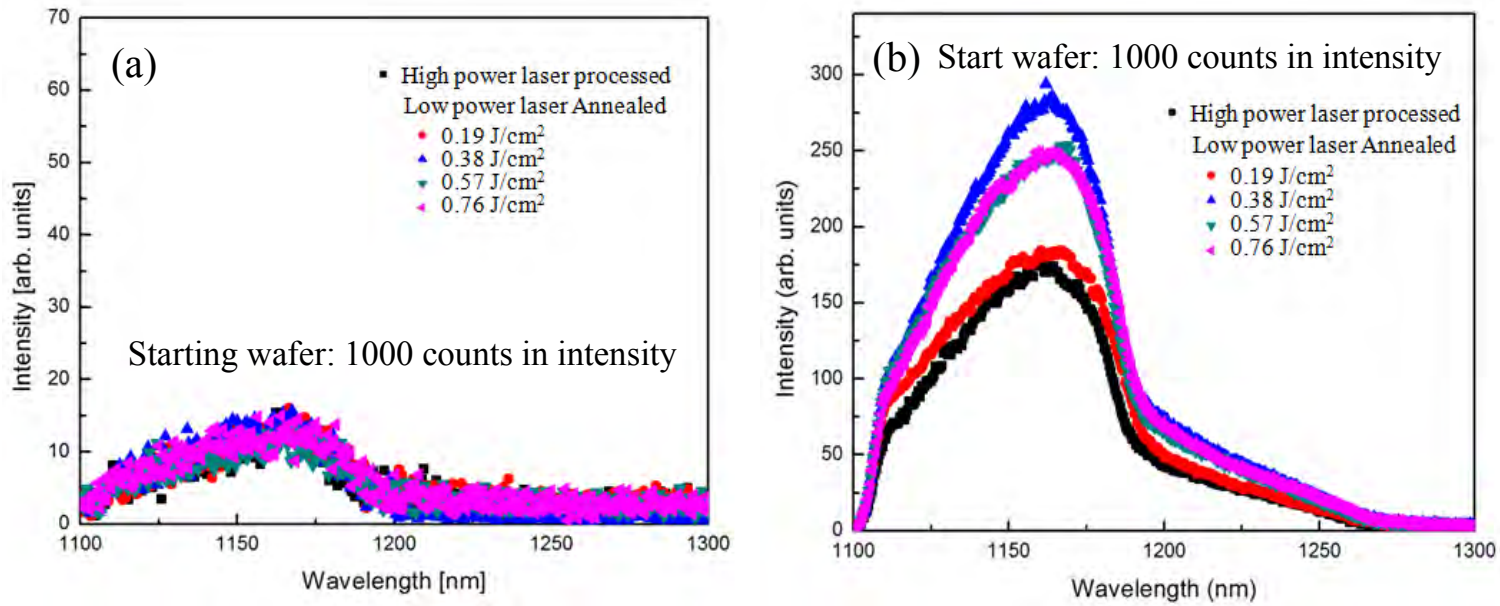

Fig. 5 PL due to band-to-band emission after laser annealing at different fluences: (a) 1.60 $\mathrm{J} / \mathrm{cm}^{2}$ - fluence processed samples, (b) $1.28 \mathrm{~J} / \mathrm{cm}^{2}$ - fluence processed samples.

The etch pits after laser annealing under various fluences were observed in the SEM images, as shown in Fig. 6 for $1.60 \mathrm{~J} / \mathrm{cm}^{2}$-fluence processed samples and in Fig. 7 for $1.28 \mathrm{~J} / \mathrm{cm}^{2}$-fluence processed samples. The corresponding dislocation density is summarized in Table I. After 0.38 $\mathrm{J} / \mathrm{cm}^{2}$-fluence annealing of $1.60 \mathrm{~J} / \mathrm{cm}^{2}$-fluence processed samples, the number of dislocations decreases dramatically as observed by comparison of Fig. 6(a) and 6(b), and quantitatively, the dislocation density drops by 3.7 times after laser annealing. This result matches with the PL dislocation-peak decrease by 4 times.

The dislocation density of $1.28 \mathrm{~J} / \mathrm{cm}^{2}$-fluence processed samples is initially 5 times lower than $1.60 \mathrm{~J} / \mathrm{cm}^{2}$-fluence processed samples. Although the initial low dislocation density limited the influence of laser annealing, it still drops to half after laser annealing at $0.38 \mathrm{~J} / \mathrm{cm}^{2}$-fluence.

When the laser annealing fluence increases higher than $0.57 \mathrm{~J} / \mathrm{cm}^{2}$, the dislocation density is observed to slightly increase. This behavior is true for both groups of processed samples, and it also matches the PL results. The best annealing performance of $0.38 \mathrm{~J} / \mathrm{cm}^{2}$ fluence is again demonstrated, so this parameter is chosen as the standard annealing condition. 

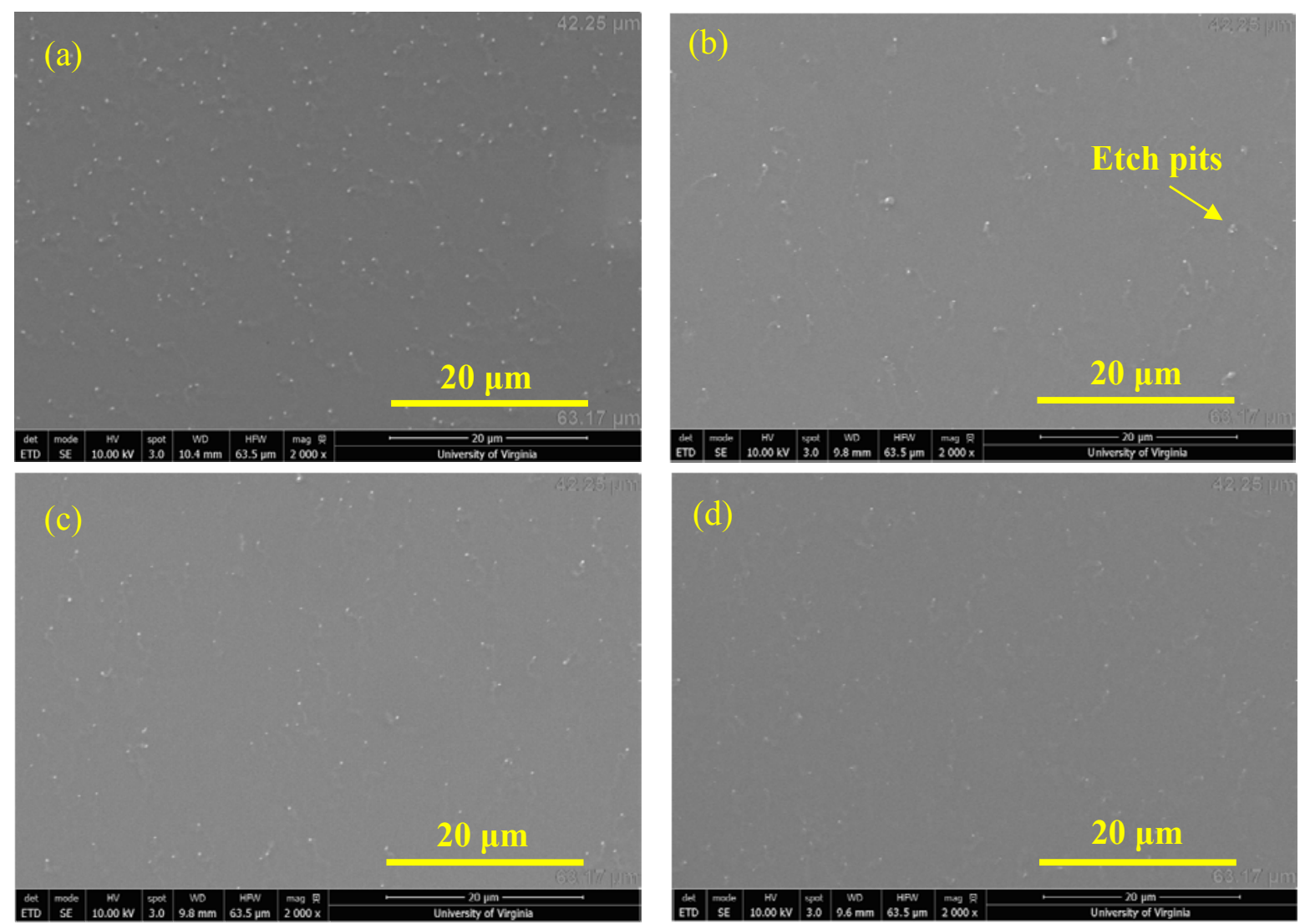

Fig. 6 SEM images for $1.60 \mathrm{~J} / \mathrm{cm}^{2}$-fluence processed samples showing etch pits: (a) Initial sample, (b) $0.38 \mathrm{~J} / \mathrm{cm}^{2}$-fluence annealing, (c) $0.57 \mathrm{~J} / \mathrm{cm}^{2}$-fluence annealing, (d) $0.76 \mathrm{~J} / \mathrm{cm}^{2}$ fluence annealing.

Table I. Summary of dislocation density after laser annealing under various fluences

\begin{tabular}{|c|c|c|c|c|}
\hline & $\begin{array}{c}\text { Initial processed } \\
\text { sample }\end{array}$ & \multicolumn{3}{|c|}{ After laser annealing under various fluences } \\
\cline { 3 - 5 } & $0.38 \mathrm{~J} / \mathrm{cm}^{2}$ & $0.57 \mathrm{~J} / \mathrm{cm}^{2}$ & $0.76 \mathrm{~J} / \mathrm{cm}^{2}$ \\
\hline $\begin{array}{l}1.60 \mathrm{~J} / \mathrm{cm}^{2} \text {-fluence } \\
\text { processed samples }\end{array}$ & $10.6 \times 10^{6} \mathrm{~cm}^{-2}$ & $2.85 \times 10^{6} \mathrm{~cm}^{-2}$ & $2.96 \times 10^{6} \mathrm{~cm}^{-2}$ & $4.08 \times 10^{6} \mathrm{~cm}^{-2}$ \\
\hline $\begin{array}{l}1.28 \mathrm{~J} / \mathrm{cm}^{2} \text {-fluence } \\
\text { processed samples }\end{array}$ & $2.17 \times 10^{6} \mathrm{~cm}^{-2}$ & $1.01 \times 10^{6} \mathrm{~cm}^{-2}$ & $1.08 \times 10^{6} \mathrm{~cm}^{-2}$ & $1.27 \times 10^{6} \mathrm{~cm}^{-2}$ \\
\hline
\end{tabular}

Table II. Summary of charge carrier lifetime before and after laser annealing

\begin{tabular}{|c|c|c|c|}
\hline & Starting wafer & Initial processed sample & After laser annealing at $0.38 \mathrm{~J} / \mathrm{cm}^{2}$ \\
\hline $\begin{array}{l}1.60 \mathrm{~J} / \mathrm{cm}^{2} \text {-fluence } \\
\text { processed samples }\end{array}$ & $1240 \mu \mathrm{s}$ & $10 \mu \mathrm{s}$ & $54 \mu \mathrm{s}$ \\
\hline $\begin{array}{l}1.28 \mathrm{~J} / \mathrm{cm}^{2} \text {-fluence } \\
\text { processed samples }\end{array}$ & $1240 \mu \mathrm{s}$ & $720 \mu \mathrm{s}$ & $920 \mu \mathrm{s}$ \\
\hline
\end{tabular}



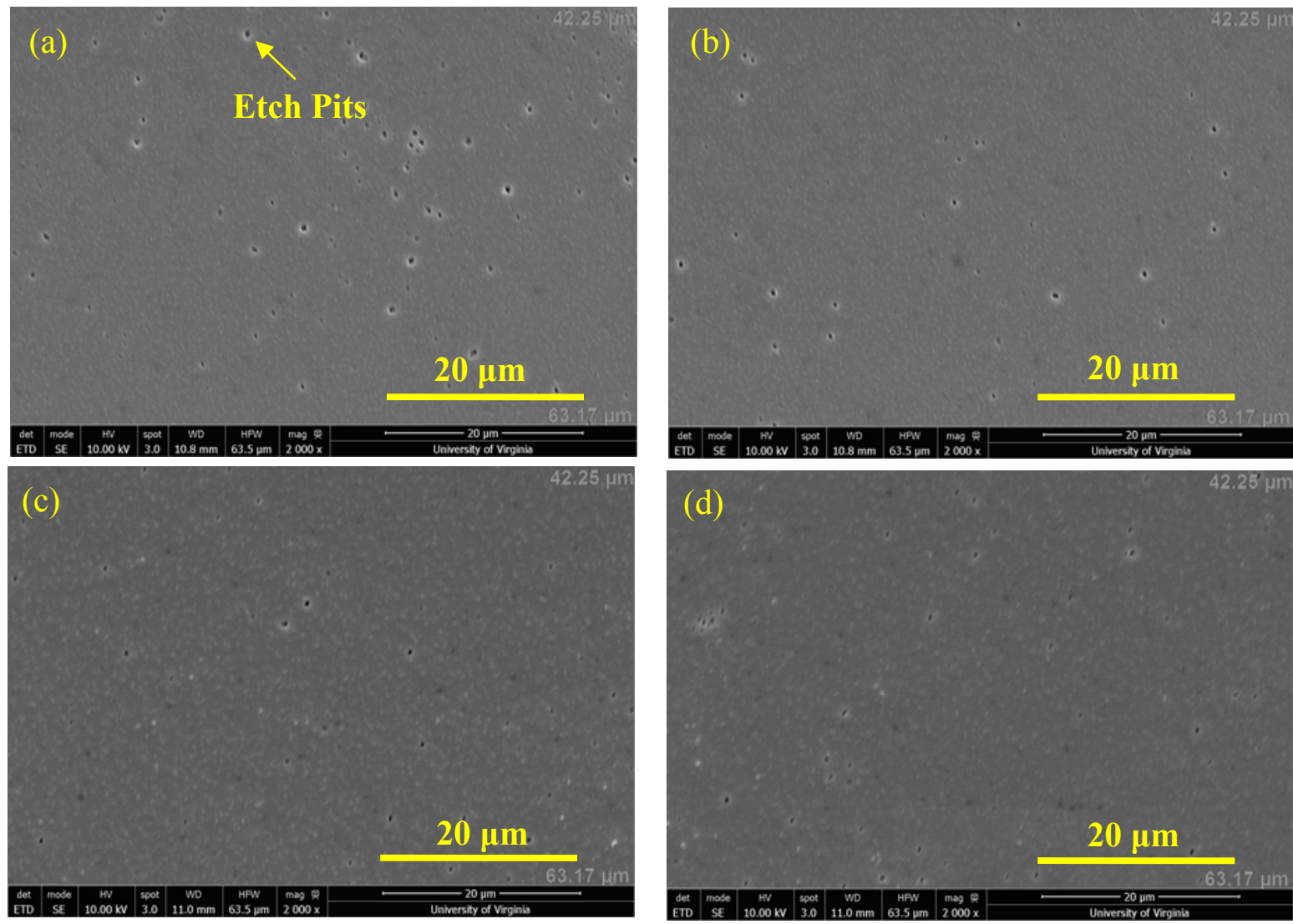

Fig. 7 SEM images for $1.28 \mathrm{~J} / \mathrm{cm}^{2}$-fluence processed samples showing etch pits: (a) Initial sample, (b) $0.38 \mathrm{~J} / \mathrm{cm}^{2}$-fluence annealing, (c) $0.57 \mathrm{~J} / \mathrm{cm}^{2}$-fluence annealing, (d) $0.76 \mathrm{~J} / \mathrm{cm}^{2}$ fluence annealing.
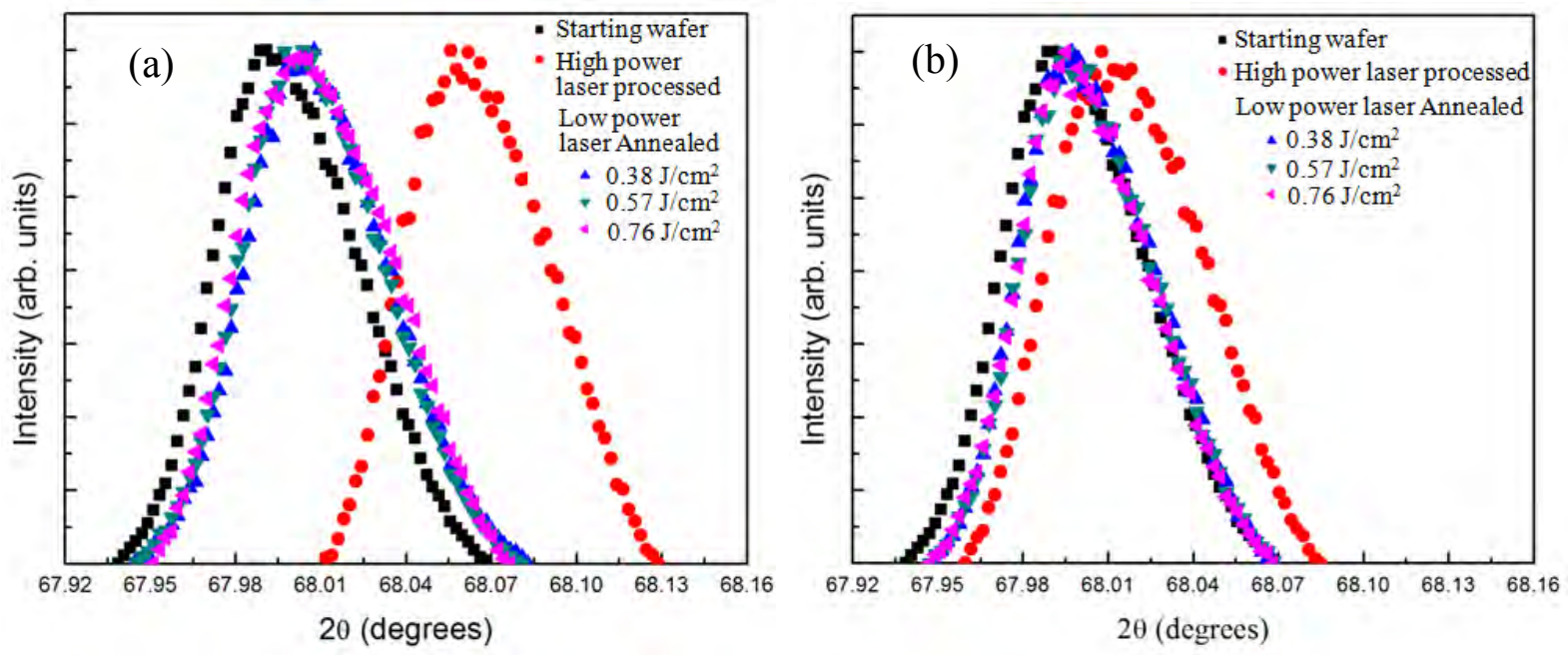

Fig. 8 XRD patterns showing the silicon peak shifting after laser processing and annealing:

(a) $1.60 \mathrm{~J} / \mathrm{cm}^{2}$-fluence processed samples, (b) $1.28 \mathrm{~J} / \mathrm{cm}^{2}$-fluence processed samples.

The XRD patterns of silicon peaks were investigated to study the change of internal stress after laser annealing. The effective depth of diffracted X-ray radiation is around $10 \mu \mathrm{m}$ [18], thus most internal stress information in the melted and annealing region (around $8 \mu \mathrm{m}$ ) can be detected by XRD. As shown in Fig. 8(a), the silicon peak shows a right shifting of $0.08^{\circ}$ 
(resolution: $0.002^{\circ}$ ) after the starting wafer is processed under $1.60 \mathrm{~J} / \mathrm{cm}^{2}$ laser fluence. This right shifting is due to the compressive stress generated by laser processing. After the laser annealing under $0.38 \mathrm{~J} / \mathrm{cm}^{2}, 0.57 \mathrm{~J} / \mathrm{cm}^{2}$, and $0.76 \mathrm{~J} / \mathrm{cm}^{2}$ fluences, we find the silicon peak shifts towards the position for the starting wafer. A similar behavior is also observed in $1.28 \mathrm{~J} / \mathrm{cm}^{2}$ fluence processed samples, as shown in Fig. 8(b), but the shifting is smaller than $1.60 \mathrm{~J} / \mathrm{cm}^{2}$ fluence processed samples. This is because a smaller internal stress is induced during $1.28 \mathrm{~J} / \mathrm{cm}^{2}$ fluence processing.

Moreover, the difference of XRD peak shifting between $0.38 \mathrm{~J} / \mathrm{cm}^{2}$ and higher laser annealing fluences is very small. This behavior indicates a higher low-power laser annealing fluence does not significantly affect internal stresses, thus $0.38 \mathrm{~J} / \mathrm{cm}^{2}$ fluence again shows to be the best laser annealing condition.

The PCD curves after laser annealing are shown in Fig. 9. The photoconductance decay is divided into two stages: surface decay and later the bulk decay. The exponential fitting is applied for the surface decay to calculate the carrier lifetime where the laser energy is absorbed. The surface lifetime before and after laser annealing are summarized in Table II. As shown, the surface lifetime of $1.28 \mathrm{~J} / \mathrm{cm}^{2}$-fluence processed samples increases to $920 \mu$ s after laser annealing. This value is comparable to the initial value of $1240 \mu \mathrm{s}$, indicating the success of laser annealing to achieve a lower carrier recombination.

For $1.60 \mathrm{~J} / \mathrm{cm}^{2}$-fluence processed samples, the surface carrier lifetime also increases by 5 times, but the absolute value is still low. This behavior suggests that even though the dislocation removal is excellent for $1.60 \mathrm{~J} / \mathrm{cm}^{2}$-fluence processed samples, other factors such as laser induced polycrystalline phases can dominate in determining the carrier lifetime.
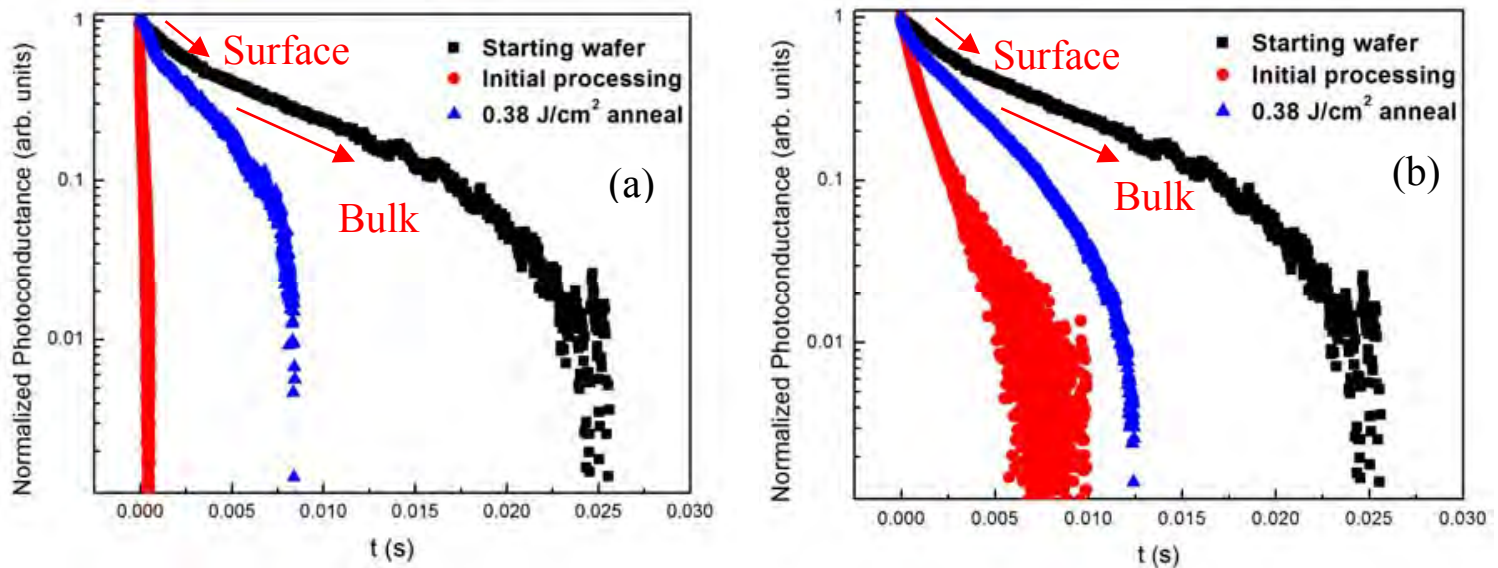

Fig. 9 PCD curves after laser annealing: (a) $1.60 \mathrm{~J} / \mathrm{cm}^{2}$-fluence processed samples, (b) $1.28 \mathrm{~J} / \mathrm{cm}^{2}$-fluence processed samples.

\section{4, Conclusions}

The laser annealing is demonstrated to be effective in lowering the surface defects of crystalline silicon after the initial high power laser processing. The $0.38 \mathrm{~J} / \mathrm{cm}^{2}$ laser fluence is found to be the best annealing parameter for removing crystal defects. For $1.28 \mathrm{~J} / \mathrm{cm}^{2}$-fluence processed samples, the dislocation density is decreased from the initial value of $2.17 \times 10^{6} \mathrm{~cm}^{-2}$ to $1.01 \times 10^{6} \mathrm{~cm}^{-2}$ after laser annealing, along with the crystallization of amorphous phase and a decrease of internal stress. These annealing results show an excellent surface carrier lifetime of $920 \mu \mathrm{s}$, which is approaching to the value for starting wafer of $1240 \mu \mathrm{s}$. For $1.60 \mathrm{~J} / \mathrm{cm}^{2}$-fluence processed samples, the dislocation density is decreased by 4 times from the initial value of 
$10.6 \times 10^{6} \mathrm{~cm}^{-2}$ to $2.85 \times 10^{6} \mathrm{~cm}^{-2}$ after laser annealing, and the internal stress is also dramatically decreased, resulting in the improvement of surface carrier lifetime by 5 times. The increase of surface carrier lifetime implies a lower carrier recombination, and will lead to a higher efficiency in the photovoltaic devices.

\section{Acknowledgements}

We acknowledge the support of NSF under the grant number CMMI-1436775, NASA Langley Professor Program, and NSF I/UCRC award.

\section{References}

[1]M.A. Green, The path to $25 \%$ silicon solar cell efficiency: History of silicon cell evolution, Prog. Photovoltaics 17 (2009) 183-189.

[2]L. Wang, D.E. Carlson, M.C. Gupta, Silicon solar cells based on all-laser-transferred contacts, Prog. Photovoltaics 23 (2015) 61-68.

[3]V.V. Iyengar, B.K. Nayak, M.C. Gupta, Optical properties of silicon light trapping structures for photovoltaics, Sol. Energ. Mat. Sol. Cells 94 (2010) 2251-2257.

[4]S.J. Eisele, T.C. Roder, J.R. Kohler, J.H. Werner, 18.9\% efficient full area laser doped silicon solar cell, Appl. Phys. Lett. 95 (2009) 133501.

[5]F. Haase, E.G. Rojas, K. Bothe, R. Brendel, Layer selective laser ablation for local contacts to thin emitters, Energy Procedia 8 (2011) 577-580.

[6]L. Zhang, H. Shen, Z. Yang, J. Jin, Shunt removal and patching for crystalline silicon solar cells using infrared imaging and laser cutting, Prog. Photovoltaics 18 (2010) 54-60.

[7]D. Kray, S. Hopmana, A. Spiegel, B. Richerzhagen, G.P. Willeke, Study on the edge isolation of industrial silicon solar cells with waterjet-guided laser, Sol. Energ. Mat. Sol. Cells 91 (2007) 1638-1644.

[8]M.D. Abbott, P.J. Cousins, F.W. Chen, J.E. Cotter, Laser-induced defects in crystalline silicon solar cells, Proc. 31st IEEE Photovolt. Spec. Conf., Orlando, 2005, pp. 1241-1244.

[9] V.V. Iyengar, B.K. Nayak, K.L. More, H.M. Meyer III, M.D. Biegalski, J.V. Li, M.C. Gupta, Properties of ultrafast laser textured silicon for photovoltaics, Sol. Energ. Mat. Sol. Cells 95 (2011) 2745-2751.

[10]B. Hartiti, R. Schindler, A. Slaoui, B. Wagner, J.C. Muller, I. Reis, A. Eyer, P. Siffert, Towards high-efficiency silicon solar cells by rapid thermal processing, Prog. Photovoltaics 2 (1994) 129-142.

[11]P. Doshi, J. Mejia, K. Tate, A. Rohatgi, Modeling and characterization of high-efficiency silicon solar cells fabricated by rapid thermal processing, screen printing, and plasma-enhanced chemical vapor deposition, IEEE Trans. Electron Devices 44 (1997) 1417-1424.

[12]P. Baeri, E. Rimini, Laser annealing of silicon, Mater. Chem. Phys. 46 (1996) 169-177.

[13]Y. Qiu, F. Cristiano, K. Huet, F. Mazzamuto, G. Fisicaro, A.L. Magna, M. Quillec, N. Cherkashin, H. Wang, S. Duguay, D. Blavette, Extended defects formation in nanosecond laserannealed ion implanted silicon, Nano Lett. 14 (2014) 1769-1775.

[14] S.A.G.D. Correia, J. Lossen, M. Wald, K. Neckermann, M. Bahr, Selective laser ablation of dielectric layers, Proc. 22nd EPVSEC, Milan, 2007, pp. 1061-1067.

[15]K.E. Bean, Anisotropic etching of silicon, IEEE Trans. Electron Devices 25 (1978), 11851193.

[16]P.J. Drummond, D. Bhatia, A. Kshirsagar, S. Ramani, J. Ruzyllo, Studies of photoconductance decay method for characterization of near-surface electrical properties of semiconductors, Thin Solid Films 519 (2011), 7621-7626. 
[17]Y. Koshka, S. Ostapenko, I. Tarasov, S. Mchugo, and J.P. Kalejs, Scanning roomtemperature photoluminescence in polycrystalline silicon, Appl. Phys. Lett. 74 (1999), 15551557.

[18] P.S. Prevey, Practical Applications of Residual Stress Technology, American Society for Metals, Materials Park, OH, 1991, pp. 47-54. 